\title{
MicroRNA-31-3p Is Involved in Substance P (SP)- Associated Inflammation in Human Colonic Epithelial Cells and Experimental Colitis
}

Kai Fang, ${ }^{*}$ Ivy Ka Man Law, ${ }^{*}$ David Padua, ${ }^{*}$ Aristea Sideri, ${ }^{*}$ Vanessa Huang, ${ }^{*}$ Christopher G. Kevil, ${ }^{\dagger}$ Dimitrios Iliopoulos, ${ }^{\ddagger}$ and Charalabos Pothoulakis*

From the Inflammatory Bowel Disease Center, ${ }^{*}$ and the Center for Systems Biomedicine, ${ }^{\ddagger}$ Vatche and Tamar Manoukian Division of Digestive Diseases, David Geffen School of Medicine at University of California at Los Angeles, Los Angeles, California; and the Department of Pathology, ${ }^{\dagger}$ Louisiana State University Health Sciences Center, Shreveport, Louisiana

Accepted for publication October 30, 2017.

Address correspondence to Charalabos Pothoulakis, M.D., Division of Digestive Diseases, Inflammatory Bowel Disease Center, David Geffen School of Medicine, University of California at Los Angeles, 675 Charles E Young Dr., S. MRL Bldg. 1240, Los Angeles, CA 90095. E-mail: cpothoulakis@mednet.ucla.edu.

\begin{abstract}
Substance $P(S P)$ mediates colitis. SP signaling regulates the expression of several miRNAs, including miR-31-3p, in human colonocytes. However, the role of miR-31-3p in colitis and the underlying mechanisms has not been elucidated. We performed real-time PCR analysis of miR-31-3p expression in human colonic epithelial cells overexpressing neurokinin-1 receptor (NCM460 NK-1R) in response to SP stimulation and in NCM460 cells after IL-6, IL8, tumor necrosis factor (TNF)- $\alpha$, and interferon- $\gamma$ exposure. Functions of miR-31-3p were tested in NCM460-NK-1R cells and the trinitrobenzene sulfonic acid (TNBS) and dextran sodium sulfate (DSS) models of colitis. Targets of miRNA-31-3p were confirmed by Western blot analysis and luciferase reporter assay. Jun N-terminal kinase inhibition decreased SPinduced miR-31-3p expression. miR-31-3p expression was increased in both TNBS- and DSS-induced colitis and human colonic biopsies from ulcerative colitis, compared with controls. Intracolonic administration of a miR-31-3p chemical inhibitor exacerbated TNBS- and DSS-induced colitis and increased colonic TNF- $\alpha$, CXCL10, and chemokine (C-C motif) ligand 2 (CCL2) mRNA expression. Conversely, overexpression of miR-31-3p ameliorated the severity of DSS-induced colitis. Bioinformatic, luciferase reporter assay, and Western blot analyses identified RhoA as a target of miR-31-3p in NCM460 cells. Constitutive activation of RhoA led to increased expression of CCL2, IL6, TNF- $\alpha$, and CXCL10 in NCM460-NK-1R cells on SP stimulation. Our results reveal a novel SP-miR-31-3p-RhoA pathway that protects from colitis. The use of miR-31-3p mimics may be a promising approach for colitis treatment. (Am J Pathol 2018, 188: 586-599; https://doi.org/10.1016/j.ajpath.2017.10.023)
\end{abstract}

miRNAs are short (19 to 22 nucleotides), single-stranded RNA molecules that negatively regulate gene expression by inducing mRNA degradation and/or inhibition of target mRNA translation. ${ }^{1}$ Functional studies have demonstrated that miRNAs play a critical role in many pathologic conditions, including inflammation ${ }^{2}$ and pathogenesis of colitis. ${ }^{3-5}$

Substance P (SP) is a neuropeptide expressed in the central nervous system and several peripheral organs, including the intestine. ${ }^{6}$ SP plays a critical role in colitis pathophysiology by interacting with its high-affinity neurokinin-1 receptor $(\mathrm{NK}-1 \mathrm{R})^{7-9}$ and activating signaling pathways related to NF- $\kappa \mathrm{B}^{10-12}$ and Jun N-terminal kinase
$(\mathrm{JNK})^{13}$ in different cell types, including colonocytes. $^{10,13,14} \mathrm{SP}$ is expressed in inflammatory cells in mice. $^{15}$ In addition, SP and NK-1R expressions are increased in the colon of inflammatory bowel disease (IBD) patients, $6,16,17$ further suggesting a critical role for the

Supported by US Public Health Service grants R01 DK47343 (C.P.) and R01 DK60729 (C.P.), Neuroendocrine Assay Core grants P50 DK64539 (C.P.) and R01 DK110003 (D.I.), a CURE: Digestive Diseases Research Center (DDRC) grant P30 DK 41301 Pilot and Feasibility study (K.F.), and Animal Core (C.P. and K.F.).

Disclosures: None declared. 
SP-NK-1R interactions in IBD pathogenesis. Along these lines, human colonic epithelial cells overexpressing NK-1R (NCM460-NK-1R) were selected to study SP-NK-1R signaling functions in colonic epithelial cells in vitro. Recently, microarray analysis indicated that among others miR-31-3p is induced by SP stimulation of NCM460-NK$1 \mathrm{R}$ cells. ${ }^{18}$

The sequence of miR-31-3p is identical in humans, cows, dogs, rats, and mice, suggesting that it may play an important physiological regulatory role. ${ }^{19}$ Recent studies demonstrated that miR-31-3p is associated with colorectal cancer, ${ }^{20,21}$ whereas SP-NK-1R interactions are involved in both IBD-associated colitis and colitis-associated cancer. ${ }^{6}$ From these considerations, it was hypothesized that the SPregulated miR-31-3p may be involved in the pathophysiology of colitis. To address this hypothesis, the mechanisms of regulation of miR-31-3p expression by SP and proinflammatory cytokines were studied, its signaling in human colonic epithelial cells examined, and its function in experimental colitis models determined.

\section{Materials and Methods}

\section{Cell Studies and Reagents}

NCM460 human colonic epithelial cells overexpressing NK-1R (NCM460-NK-1R) were cultured as previously described $^{10}$; cells were starved in serum-free medium overnight and then stimulated with $0.1 \mu \mathrm{mol} / \mathrm{L}$ SP concentration at the indicated times. The JNK inhibitor SP600125 (catalog number 8177) was from Cell Signaling Technology (Danvers, MA). SP (catalog number S6883) was purchased from Sigma-Aldrich (St. Louis, MO). IL-6 (catalog number 7270-IL-025), IL-8 (catalog number 618-IL-010), tumor necrosis factor (TNF)- $\alpha$ (catalog number 210-TA), and interferon- $\gamma$ (catalog number 285-IF) were purchased from R\&D Systems (Minneapolis, MN). Protease inhibitor cocktail (catalog number sc-29130) was purchased from Santa Cruz Biotechnology (Dallas, TX). Rabbit anti-RhoA (catalog number SC-26C4) and mouse anti-c-Jun (catalog number SC-74543) antibodies were purchased from Santa Cruz Biotechnology. Mouse anti- $\beta$-actin (catalog number A5316) was purchased from Sigma-Aldrich. RhoA L63 recombinant adenovirus (constitutively active, ADV-157) and null control recombinant adenovirus(ADV-001) were purchased from Cell Biolabs, Inc. (San Diego, CA). Rho activation assay kit (catalog number BK036) was purchased from Cytoskeleton, Inc. (Denver, CO). Human RhoA siRNA (catalog number SC-29471), c-Jun siRNA (catalog number SC-29223), and control siRNA (SC-37007) were purchased from Santa Cruz Biotechnology. Lipofectamine 2000 (catalog number 52758) was purchased from Life Technologies (Carlsbad, CA). Dextran sodium sulfate (DSS; catalog number 9011-18-1) was from Affymetrix (Canoga Park, CA). Trinitrobenzene sulfonic acid (TNBS) was from Sigma-Aldrich (catalog number 92822).

\section{Human IBD Biopsy Specimens}

Total RNAs from the colon tissues of patients with active ulcerative colitis (UC) $(n=14)$, active Crohn disease (CD; $n=15$ ), and healthy individuals ( $n=9$ to 10 ) were purchased from Origene (Rockville, MD). These biopsy samples were obtained from accredited US-based medical institutions through strict institutional review board protocols and with fully documented patient consent. For miRNA in situ hybridization analysis, human biopsies were obtained from patients with UC or CD, and control colon samples were obtained from non-IBD patients without abnormalities at colonoscopy or clinical history of gastrointestinal disease. These tissues were obtained from the University of California Los Angeles Medical Center through institutional review board protocols and with fully documented patient consent.

\section{Transfection Experiments}

Inhibitors of miR-31-3p (catalog number 4464084), negative anti-miRNA controls (catalog number 4464076), a miR-31-3p mimic (catalog number 4464066), and mimic miRNA controls (catalog number 4464058) were purchased from Life Technologies. Mouse anti-miR-31-3p and its negative control (sequence of anti-miR-31-3p is $5^{\prime}$ AATATGTTGGCATAGC- $3^{\prime}$, sequence of anti-miRNA control is $5^{\prime}$-ACGTCTATACGCCCA-3') were purchased from Qiagen (Germantown, MD). Lipid-based siPORTNeoFX Transfection Agent (AM4511) was purchased from Ambion (Canoga Park, CA). For miR-31-3p silencing or overexpression, cells were transfected with antisense (as)miR-31-3p or miR-31-3p mimic, respectively. Cells transfected with antisensecontrol miRNA, or miRNA-mimic control served as controls. For c-Jun or RhoA silencing, NCM460-NK-1R cells were transfected with the respective siRNA or control siRNA with the use of lipofectamine RNAiMAX from Life Technologies.

\section{Real-Time PCR Analysis}

High-capacity reverse transcription reagent for cDNA was from Applied Biosystems (catalog number 4368813; Foster City, CA). Real-time PCR primers were purchased from Life Technologies, except miR-31-3p primers that were purchased from Qiagen (catalog number 205415). Total RNA of the NCM460-NK-1R cells were isolated by using Trizol reagents, the RNA concentrations were determined by Nanodrop. Mouse serum RNA was isolated by using miRCURY RNA Isolation Kit-Biofluids (Qiagen; catalog number 300112) according to the manufacture's protocol. The miRNA template for real-time PCR analysis was prepared by using Qiagen reagents. RNU1A1 (Qiagen; catalog number 203909) expression was used as an internal control. The Ct value formula was used to calculate the relative expression of selected miRNAs, as was previously reported. ${ }^{22}$ Conversion 
of the cDNA of RNA samples was performed as previously reported, ${ }^{18}$ and the levels of mRNA expression were determined by quantitative real-time PCR analysis. All of the primers were purchased from Thermo Fisher Scientific (Waltham, MA): human IL-6 (Hs00174131_m1); chemokine (C-C motif) ligand 2 (CCL2; Hs00234140_m1); IL-1B (Hs00173097_m1); TNF- $\alpha$ (Hs01113624_g1); CXCL10 (Hs01124251_g1); RhoA (Hs00357608_m1); mouse IL-6 (Mm00446190_m1); CCL2 (Mm00441242_m1); mouse TNF- $\alpha$ (Mm00443258-m1), and CXCL10 (Mm00445235m1). Human 18S (Hs03928990_g1) or mouse 18S (Mm03928990_g1) gene expression was selected as an internal control.

\section{Adenovirus Infection}

Human colonic epithelial cells seeded at a density of $6 \times 10^{4}$ cells per well in 6-well plates were incubated in complete medium overnight and then incubated with 200 $\mathrm{pfu} / \mathrm{cell}$ of Ad-RhoA-L63 or null control recombinant adenovirus in serum-free medium for 1 hour, followed by incubation in compete medium for 24 hours, as previously reported. $^{23}$

\section{Immunoblot Analysis}

NCM460-NK-1R cells were washed with ice-cold phosphate-buffered saline (PBS) and incubated with radiolabeled immunoprecipitation assay buffer that contained the protease inhibitors and sodium orthovanadate (Santa Cruz Biotechnology) for 5 minutes on ice. Equal amounts of cell lysates were subjected to sodium dodecyl sulfatepolyacrylamide gel electrophoresis and transferred to polyvinylidene difluoride membranes. Membranes were blocked (PBS, 5\% nonfat dry milk, $0.05 \%$ Tween-20) and probed with antibodies, followed by corresponding horseradish peroxidase-labeled secondary antibodies. Blots were developed with an enhanced chemiluminescence reagent from Thermo Fisher Scientific (catalog number 34080). The signal was quantified by using ImageJ software version 1.47 (NIH, Bethesda, MD).

\section{RhoA Activation Assay}

RhoA activity was measured according to the procedure provided in the Rho Activation Assay Biochem Kit (Cytoskeleton, Inc.; catalog number BK036) manual. Cells were washed with PBS and then incubated with lysis buffer for 10 minutes at $4^{\circ} \mathrm{C}$. Cell lysates were centrifuged at 10,000 $\times g$ for 1 minute. An equal amount of rhotekin-RBD beads was incubated with the fresh equal amount of supernatants for 1 hour of rotation at $4^{\circ} \mathrm{C}$, and the beads were then washed with wash buffer. Equal volumes of the samples were subjected then to Western blot analysis by using a monoclonal antibody against RhoA. To normalize the amount of protein of the samples, equal volumes of cells lysates were subjected to Western blot analysis by using a $\beta$-actin antibody.

\section{Luciferase Assays}

RhoA $3^{\prime}$ untranslated region (UTR) that contained the predicted binding sites and mutated sequence was chemically synthesized by GENEWIZ (South Plainfield, NJ). The wild-type and mutant of the RhoA $3^{\prime}$ UTR sequence were then subcloned into the luciferase reporter vector purchased from SwitchGear Genomics (catalog number 32011; Carlsbad, CA). Luciferase reporter constructs that contained the wild-type or mutant of $3^{\prime}$ UTR of RhoA were transfected to NCM460-NK-1R cells by using lipofectamine 2000 (Invitrogen, Carlsbad, CA) with miR-31-3p mimic or control mimic. Cell lysates were prepared 24 hours after transfection, and luciferase activity was measured by using the LightSwitch Luciferase Assay Kit (catalog number LS100) from SwitchGear Genomics according to the manufacturer's instructions.

\section{In Situ Hybridization}

In situ hybridization was performed on mice colon tissue from C57BL/6J mice after treatment of DSS or TNBS, or human $\mathrm{UC}$, or $\mathrm{CD}$ and control colon tissue, as was previously reported. ${ }^{24}$ The sequence of the probe specific for miR-31-3p (catalog number 39840-15) was as follows: 5'-GATGGCAATATGTTGGCATAGCA-3'. The hybridization was performed according to the manufacturer's instructions by using miRCURY LNA microRNA ISH Optimization Kit (formalin-fixed, paraffin-embedded; Qiagen).

\section{Experimental Colitis}

DSS, TNBS, and T-cell-transfer colitis were induced as previously described, ${ }^{22,24}$ and animal studies were approved by the institutional animal care and use committee. NK-1R knockout (KO) mice were purchased from The Jackson Laboratories (Bar Harbor, ME) and bred in the University of California Los Angeles animal facility. Total RNA from the colonic tissues of TNBS and T-cell-transfer colitis models were purified by use of the miReasy Mini Kit (Qiagen, Valencia, CA) and from the DSS model by use of the lithium chloride precipitation method. ${ }^{25}$ The body weight of DSS and TNBS colitis mice was monitored daily. Colon tissue sections were observed under $10 \times$ objective lens and scored for histopathologic analysis in a double-blinded manner (I.K.M.L. and D.P.) as previously reported. ${ }^{24}$

\section{TNBS-Induced Colitis}

Six- to 8-week-old male C57BL/6J mice ( $n=5$ to 8 per group) were injected intracolonicaly with $80 \mathrm{mg} / \mathrm{kg}$ TNBS (Sigma-Aldrich) in 30\% ethanol or 30\% ethanol alone. Mice 
were sacrificed after 7 days by cervical dislocation, and colonic tissues were collected. To assess the function of miR-31-3p, mice were intracolonicaly administered with 80 $\mathrm{mg} / \mathrm{kg}$ TNBS, followed by intracolonic administration of 40 $\mu \mathrm{g}$ of miRCURY LNA inhibitor directed against mmu-miR31-3p or a control inhibitor on days 1,3 , and 5 by using a previously reported approach. ${ }^{24}$ All mice were sacrificed 7 days after TNBS administration.

\section{DSS-Induced Colitis}

C57BL/6J mice received 2\% DSS in the drinking water ad libitum for 5 days ( $n=8$ mice per group). On days 1,3 , and 5 , mice were intracolonicaly injected with $40 \mu \mathrm{g}$ of miRCURY LNA inhibitor against mmu-miR-31-3p (Qiagen) or control inhibitor as previously reported. ${ }^{24}$ In separate studies, on days 1,3 , and 5 , mice were intracolonicaly injected with $80 \mu \mathrm{g}$ of miR-31-3p AgomiR (miR-31-3p mimic, with the sequence as follows: sense strand, $5^{\prime}$ UGCUAUGCCAACAUAUUGCCAU- $3^{\prime}$; antisense strand, $5^{\prime}$-GGCAAUAUGUUGGCAUAGCAUU-3'); or control AgomiR (control mimic, with the sequence as follows: sense strand, 5'-UUCUCCGAACGUGUCACGUTT-3'; antisense strand, $5^{\prime}$-ACGUGACACGUUCGGAGAATT- ${ }^{\prime}$ ) (both from Bioland Scientific LLC, Paramount, CA). The AgomiR miR-31-3p is a chemically modified double-strand miR-31-3p mimic, having its antisense strand modified with two phosphorothioates at the $5^{\prime}$ end, four phosphorothioates at the $3^{\prime}$ end, a $3^{\prime}$ end cholesterol group and full-length nucleotide $2^{\prime}$-methoxy modification. Mice were sacrificed at day 6 by cervical dislocation, and colonic tissues were collected. A disease activity index (DAI) was calculated from measurements of mice weight loss, rectal bleeding, and stool consistency as previously reported. ${ }^{26}$

\section{T-Cell-Transfer Colitis}

Male $\left(\mathrm{Rag}^{-1-}\right.$ ) mice on C57BL/6 background aged 6 to 8 weeks were used as recipients of CD4CD45Rb ${ }^{\text {hi }}$ T-cell transfer, as previously reported. ${ }^{22} \mathrm{~T}$-cell transfer mice were sacrificed at weeks 0 and 4 ( $n=4$ for each group). Harvested colon tissue was cut in half longitudinally with one-half put in RNA later and stored at $-80^{\circ} \mathrm{C}$ and the other half fixed in $10 \%$ formaldehyde for histopathologic analysis.

\section{Statistical Analysis}

The $t$-test for two-group comparisons and analysis of variance for multiple group comparisons determined statistically significant differences between the experimental groups. For the DAI, polymorphonuclear neutrophil score, and histopathology score, the Kruskal-Wallis test was used to analyze differences between the groups. $P<0.05$ was considered statistically significant. All results were expressed as means $\pm \mathrm{SD}$.

\section{Results}

SP Regulates Expression of miR-31-3p in Human Colonic Epithelial Cells

To verify previous gene expression analysis results showing that SP treatment stimulates miR-31-3p expression in NCM460-NK-1R cells, ${ }^{18} 0.1 \mu \mathrm{mol} / \mathrm{L}$ SP was used to stimulate NCM460-NK-1R cells in serum-free medium for 0.5 and 6 hours, as previously described. ${ }^{14,27}$ Because SP modulated the development of colitis by the release of proinflammatory cytokines, ${ }^{6}$ the effects of $10 \mathrm{ng} / \mathrm{mL}$ of IL6 , IL- 8 , TNF- $\alpha$, interferon- $\gamma$, and a cytokine cocktail that included $10 \mathrm{ng} / \mathrm{mL}$ of IL- 6 , IL-8, TNF- $\alpha$, and interferon- $\gamma$ were also examined on miR-31-3p expression. Total RNA was isolated and analysis was performed as previously reported. ${ }^{18}$ Real-time PCR demonstrated that miR-31-3p expression in NCM460-NK-1R cells had a twofold increase at 6 hours after SP exposure, although no significant difference was observed 30 minutes after SP stimulation $(n=3)$ (Figure 1A). Stimulation of NCM460 cells with individual cytokines or the cytokine cocktail for 6 hours also increased miR-31-3p expression (Figure 1, B-F). Surprisingly, we did not find a synergistic effect of these cytokines on miR-31-3p expression in NCM460 cells (Figure 1F). It is possible that miR-31-3p expression had nearly reached its maximum levels (approximately twofold to fourfold) on individual proinflammatory cytokine stimulation; thus, no synergistic effect may be observed. These data, however, demonstrated that miR-31-3p was part of an inflammatory network in colonocytes.

\section{SP Regulates miR-31-3p Expression through JNK Signaling Pathway}

Because NK-1R coupling activates transcription factor $\mathrm{JNK},{ }^{10-13}$ which is involved in experimental colitis, ${ }^{28,29}$ the role was examined in JNK in SP-regulated miR-31-3p expression. In addition, bioinformatics analysis by using the transcription factor binding motifs search software TRANSFAC version 7.0 (http://www.gene-regulation.com/ pub/databases.html, last accessed November 4, 2015) indicated the presence of c-Jun binding sites (the sequence is $5^{\prime}$-GTCAATTAGT-3' , from $21,513,736$ to $21,513,727 \mathrm{bp}$ of minus strand of chromosome 9). Pretreatment of NCM460-NK-1R cells with $50 \mu \mathrm{mol} / \mathrm{L}$ of the JNK inhibitor SP600125 $5^{31}$ showed that SP-stimulated miR-31-3p expression was completely normalized by SP600125 treatment (Figure 2A). siRNA was also used against c-Jun to silence JNK expression in NCM460-NK-1R cells. c-Jun protein levels were greatly reduced by si-c-Jun silencing, compared with control siRNA-transfected cells (Figure 2B). Consistently, c-Jun silencing reduced miR-31-3p expression in response to SP $(n=3 ; P<0.05)$ (Figure 2C). These results indicated that in human colonocytes SP regulated miR-31-3p expression through JNK-dependent signaling. 

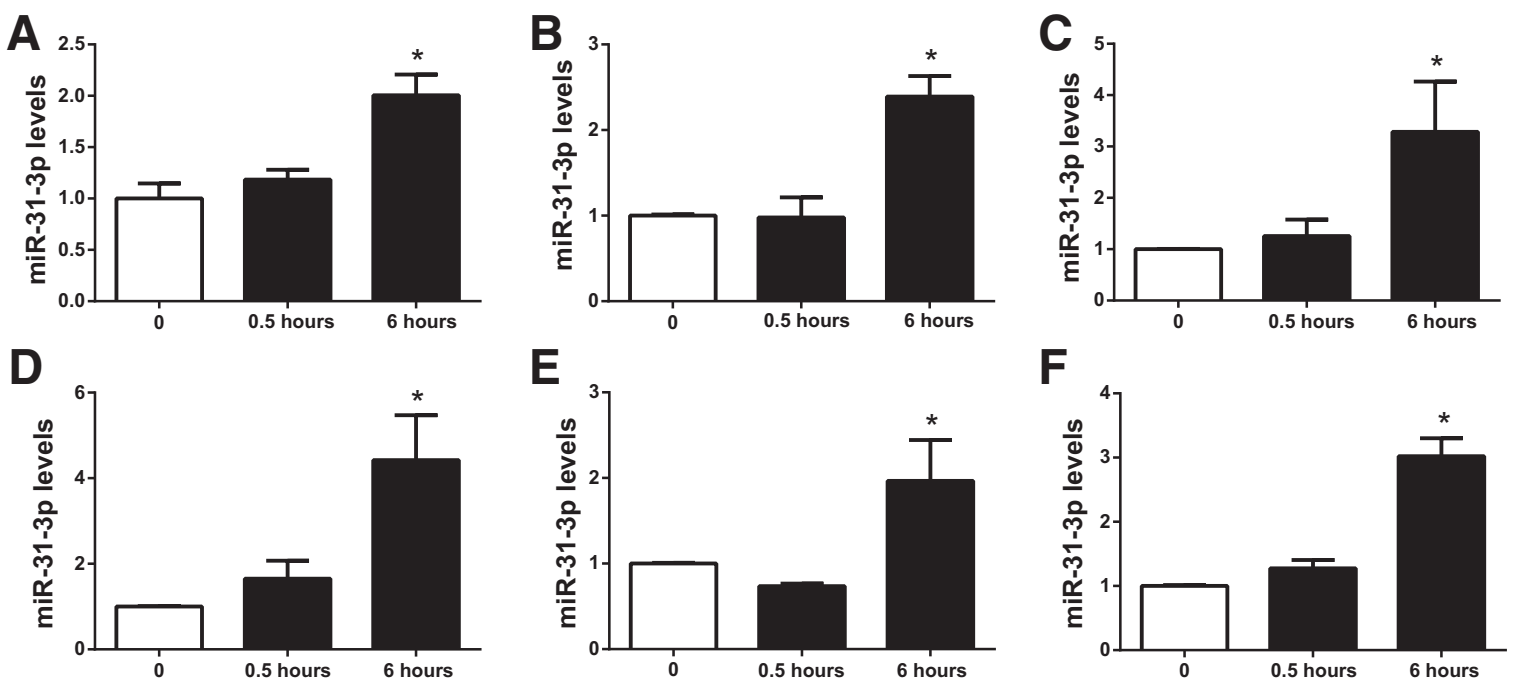

Figure 1 Substance P (SP)-regulated miR-31-3p expression in colon epithelial cells. A: SP stimulates miR-31-3p expression in NCM460-neurokinin-1 receptor (NK-1R) cells. B-F: miR-31-3p is up-regulated by IL-6 (B), interferon (IFN)- $\gamma$ (C), IL-8 (D), tumor necrosis factor (TNF)- $\alpha$ (E), and cytokine cocktail (F) in NCM460 cells. $n=3 .{ }^{*} P<0.05$ versus no SP or cytokine-stimulated cells.

\section{miR-31-3p Regulates Cytokine Gene Expression in Human Colonic Epithelial Cells}

Because SP stimulated miR-31-3p expression and inflammatory responses in colonic epithelial cells, it was next examined whether miR-31-3p was involved in SP-related cytokine gene expression. To study the miR-31-3p function in vitro, NCM460-NK-1R cells were transfected with as-miR-31-3p or miR-31-3p mimic as well as their respective controls. In NCM460-NK-1R cells as-miR-31-3p transfection suppressed miR-31-3p expression, whereas miR-31-3p mimic transfection greatly increased miR-31-3p expression $(n=3$; $P<0.05$ ) (Supplemental Figure S1). Interestingly, transfection of NCM460-NK-1R cells with as-miR-31-3p increased SP-induced CCL2 and IL-6 mRNA, compared with those transfected with control as-miR (Figure 3, A and B). Conversely, overexpressing miR-31-3p by transfection of
miR-31-3p mimic inhibited SP-induced CCL2 and IL-6 mRNA in NCM460-NK-1R cells, compared with cells transfected with control mimic $(n=3 ; P<0.05)$ (Figure 3, C and D). In addition, overexpression of miR-31-3p also inhibited cytokine cocktail-induced CCL2, IL-6, IL1-B, and TNF- $\alpha$ expression $(n=3 ; P<0.05)$ (Figure 3, E-H). Thus, miR-31-3p expression negatively regulated cytokine expression in human colonocytes under proinflammatory stimulation.

miR-31-3p Expression and Localization in Colon of IBD Patients and Mouse Colitis Models

Because NK-1R expression is increased in the colons of IBD patients, ${ }^{16,32}$ it was next examined whether miR-31-3p expression was also increased in human IBD samples. Elevated miR-31-3p expression was found in UC biopsies
A

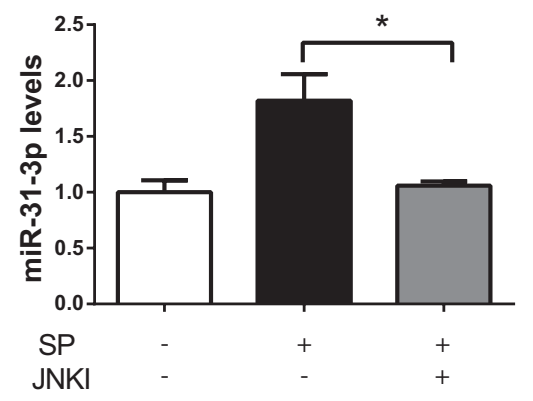

B

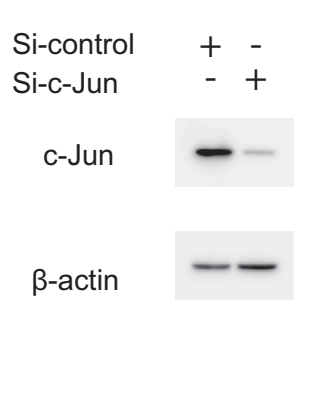

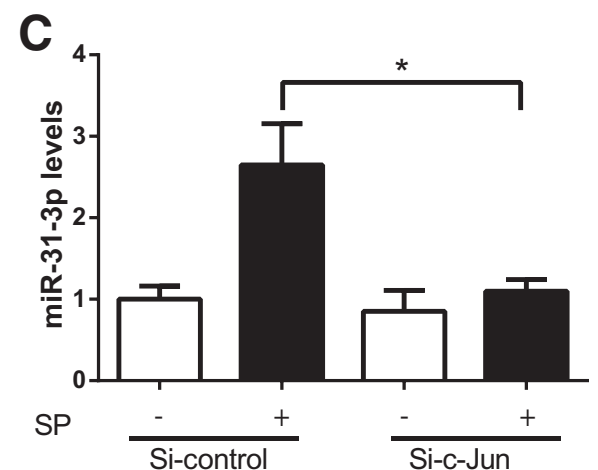

Figure 2 Substance P (SP) regulates miR-31-3p expression through a Jun amino-terminal kinase (JNK) signaling pathway. A: Expression levels of miR-31$3 p$ in SP-stimulated NCM460-neurokinin-1 receptor (NK-1R) cells pretreated with the JNK inhibitor (JNKI) SP600125. B: Expression levels of c-Jun and $\beta$-actin protein are assessed by Western blot analysis after NCM460-NK-1R cells were transfected with siRNA-c-Jun or control siRNA for 48 hours. C: Expression levels of miR-31-3p in SP-stimulated NCM460-NK-1R cells transfected with siRNA-c-Jun for 48 hours before SP exposure for 6 hours. Data are expressed as means \pm SD. $n=3$ samples per experimental condition. ${ }^{\star} P<0.05$. 

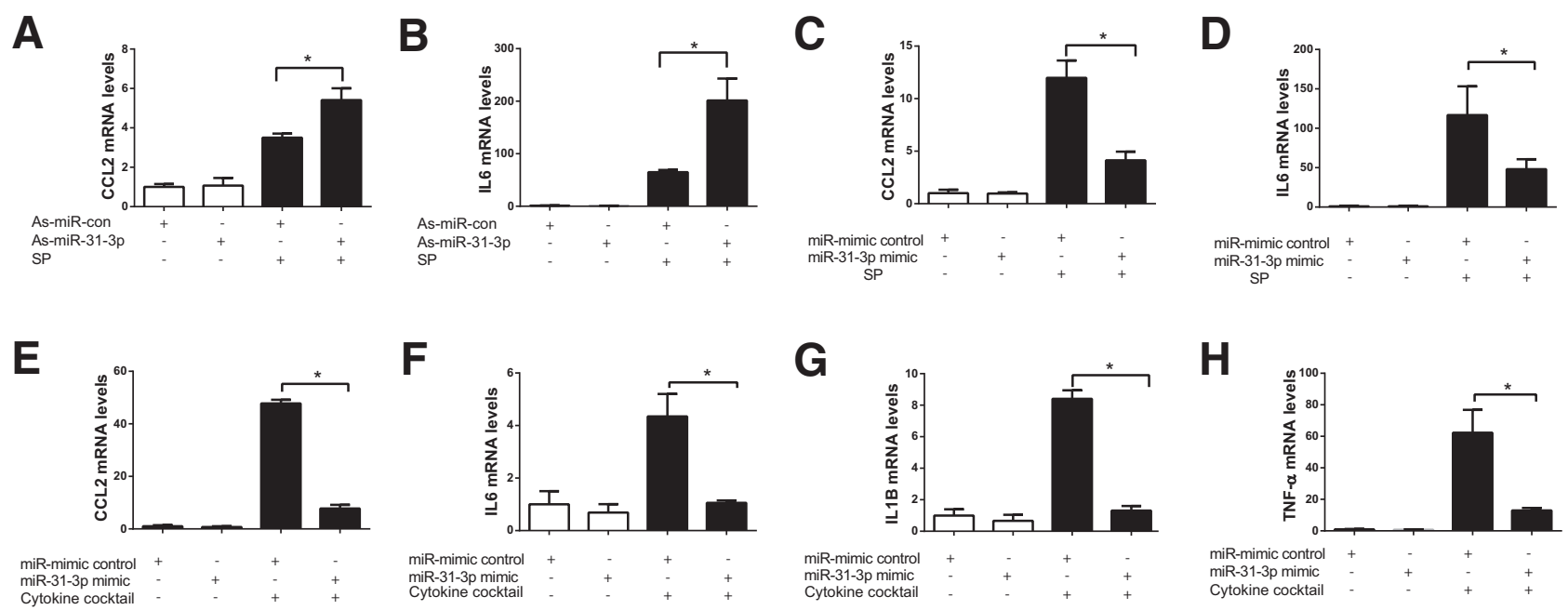

Figure 3 miR-31-3p regulates inflammatory gene expression in colonic epithelial cells. A and B: miR-31-3p down-regulation increases chemokine (C-C motif) ligand 2 (CCL2) (A) and IL-6 (B) mRNA expression in response to substance P (SP) stimulation. C and D: miR-31-3p overexpression decreases CCL2 (C) and IL-6 (D) mRNA expression in response to SP stimulation. $\mathbf{E}$ and $\mathbf{F}$ : miR-31-3p overexpression decreases CCL2 (E) and IL-6 (F) mRNA expression after incubation with a cytokine cocktail. $\mathbf{G}$ and $\mathbf{H}$ : miR-31-3p overexpression decreases IL-1B (G) and tumor necrosis factor (TNF)- $\alpha$ (H) mRNA expression in response to a cytokine cocktail. Data are expressed as means \pm SD. $n=3 .{ }^{*} P<0.05$. As, antisense; con, control.

(fivefold; $P<0.001 ; n=14$ ) compared with levels in control biopsies $(n=10)$ (Figure 4A). However, expression of miR-31-3p was not statistically significantly different in CD tissues $(n=15)$ compared with controls $(n=9$; $P>0.05$ ) (Figure 4C). To examine the cellular localization of miR-31-3p, in situ hybridization was performed by using a miR-31-3p probe in colon tissue sections obtained from control, UC, and CD patients. miR-31-3p expression was detected primarily in the epithelium of inflamed UC colon tissues, but not in control samples (Figure 4B). Similarly, in situ hybridization showed that miR-31-3p was localized in colon epithelial cells in CD samples (Figure 4D). A modest increase was found in miR-31-3p expression in CD tissues compared with control tissues, but the miR-31-3p signal was less evident compared with UC colon (Figure 4B).

To examine a functional role for miR-31-3p in colitis pathophysiology colonic expression of miR-31-3p was examined in two chemical models of experimental colitis (Figure 4, E and F). Expression of miR-31-3p was significantly increased 5 days after administration of $2 \%$ DSS $(n=5 ; P<0.05)$ (Figure 4E) and in mice after intracolonic administration of TNBS $(n=8 ; P<0.05)$ (Figure 4G). Consistent with the results from IBD patient biopsies, no detectable miR-31-3p signal was found in normal mouse colon, but an intense miR-31-3p signal was expressed primarily in the epithelial layer of colons from DSS-and TNBS-exposed mice (Figure 4, $\mathrm{F}$ and $\mathrm{H}$ ).

miR-31-3p levels were also increased by threefold in the colon of mice with chronic (4 weeks) T-cell-transfer colitis $(n=4 ; P<0.05)$ (Supplemental Figure S2). miR-31-3p levels were also measured in the serum of mice in the DSS colitis model. However, no significant difference was found in miR-31-3p levels in serum between the normal mice and DSS-treated mice (Supplemental Figure S3).
Importantly, NK-1R-deficient mice showed reduced colonic miR-31-3p levels after TNBS-induced colitis $(n=5 ; P<0.05)$ (Figure 4G), compared with wild-type mice under the same treatment. Thus, in vivo miR-31-3p expression was NK-1R dependent.

\section{Intracolonic Silencing of miR-31-3p Enhances TNBS- Induced Colitis}

The importance of miR-31-3p was next assessed in colitis pathogenesis in the TNBS colitis model, as described in Materials and Methods (Figure 5A). No significant difference was found in body weight changes between any of the mouse groups (Figure 5B). To verify efficient silencing of endogenous miR-31-3p, colonic miR-31-3p expression was measured in mouse intestine in all treatment groups, and reduced endogenous miR-31-3p levels were found $(P<0.05$, $n=8)$ in LNA-as-miR-31-3p-exposed mice compared with mice exposed to LNA-as-control miR (Figure 5C). Mice treated with TNBS showed epithelial layer destruction, inflammation, and an increased histopathology score compared with intracolonic vehicle administration $(P<0.05)$ (Figure 5, D and E). No difference was found in the histopathology score between LNA-as-miR-control- or LNA-asmiR-31-3p-treated, non-TNBS-exposed mice (Figure 5, D and E). No difference was found in colon length and colon weight (Figure 5, F and G). However, LNA-as-miR-31$3 p-$ treated TNBS-exposed mice demonstrated more prominent mucosal thickening and infiltration of immune cells (Figure 5E), increased histopathology score (Figure 5D), and significantly increased colon weight to length ratio (Figure $5 \mathrm{H}$ ) than LNA-as-miRNA-control-treated mice. A marked increase was also found in the colonic levels of cytokines important to colitis development, such as, TNF- $\alpha$, 
A

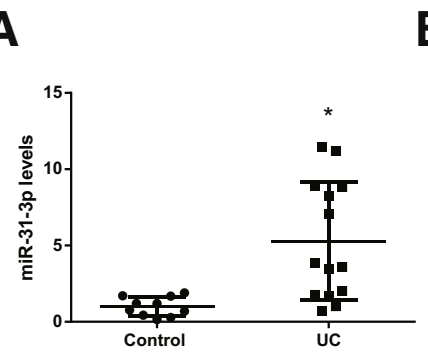

C

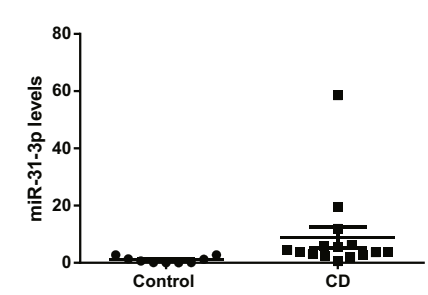

E

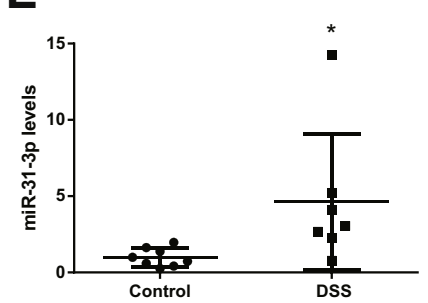

G

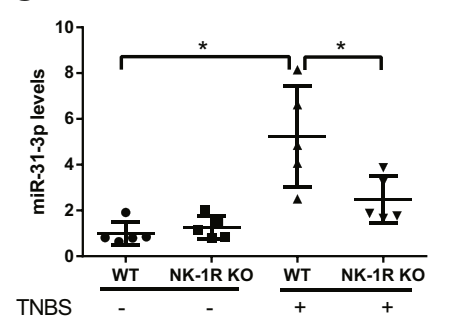

H
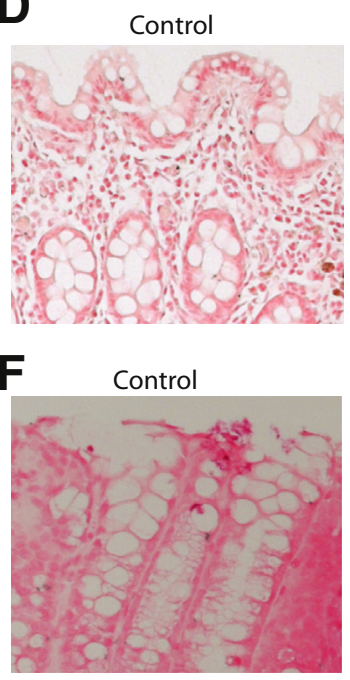

$C D$

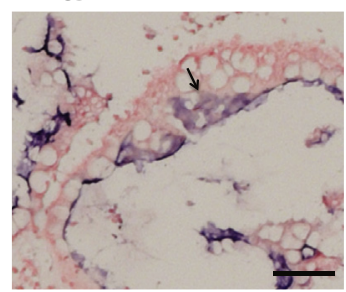

DSS

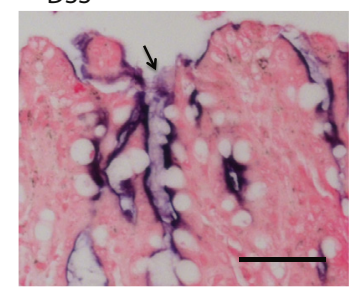

TNBS

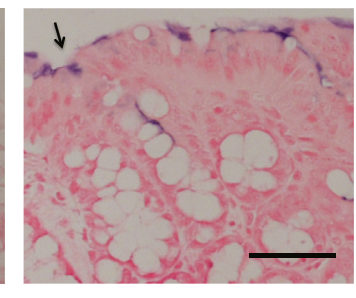

Figure 4 miR-31-3p expression increases in ulcerative colitis (UC) tissues and experimental colitis. A: Expression of miR-31-3p in human UC tissue samples compared with control tissue samples. B: Representative images of in situ hybridization of miR-31-3p of colon tissues from UC patients and controls (arrow indicates epithelial cells). C: Expression of miR-31-3p in human Crohn disease (CD) tissue samples compared with control tissue samples is shown. D: Representative images of in situ hybridization of miR-31-3p of colon tissues from CD patients and controls (arrow indicates epithelial cells). E: Expression of miR-31-3p increases in dextran sodium sulfate (DSS) colitis. F: Representative images of in situ hybridization of miR-31-3p of colon tissues from DSS-treated C57BL6/J mice and their control counterparts (arrow indicates epithelial cells). G: Expression of miR-31-3p in colon tissues from neurokinin-1 receptor (NK-1R) knockout (K0) mice and their control counterparts [wild-type (WT) mice] in trinitrobenzene sulfonic acid (TNBS)-induced colitis. H: Representative images of in situ hybridization of miR-31-3p of colon tissues from wild-type mice with or without TNBS treatment (arrow indicates epithelial cells). Data are expressed as means \pm SD. $n=14$ human UC tissue samples $(\mathbf{A})$; $n=10$ control tissue samples (A); $n=15$ human CD tissue samples (C); $n=9$ control tissue samples (C); $n=8$ control tissue samples (E); $n=7$ DSS colitis samples (E); $n=5(\mathbf{G}) . P>0.05$ control versus $\mathrm{CD}(\mathrm{C}) .{ }^{*} P<0.05$ versus control. Scale bars $=50 \mu \mathrm{m}$.
CCXL10, a neutrophil chemoattractant, CCL2, a cytokine responsible for immune cell recruitment, ${ }^{33,34}$ after silencing of miR-31-3p expression in TNBS-exposed mice (Figure 5I), suggesting that lower colonic miR-31-3p levels exacerbated TNBS-induced colitis by promoting expression of proinflammatory cytokines.

\section{LNA-as-miR-31-3p Treatment Exacerbates DSS-Induced Colitis}

To further confirm the proinflammatory effect of as-miR-31$3 p$, LNA-as-miR-31-3p or control as-miR was injected intracolonicaly to mice exposed to $2 \%$ DSS at day 1,3 , and 5 during a 6-day DSS treatment (Figure 6A). No significant difference was found in body weight change between asmiR-31-3p- and as-miR-control-treated mice (Figure 6B). Compared with LNA-as-miR-control and DSS-treated mice, treatment with LNA-as-miR-31-3p exacerbated histologic damage and colitis (Figure $6 \mathrm{C}$ ), reduced colon length (Figure 6E), and increased DAI (Figure 6F). In vivo gene silencing of miR-31-3p also increased colonic histopathology score (Figure 6G), crypt damage (Figure 6H), and mucosal edema (Figure 6I). Consistent with the results from the TNBS colitis model, LNA-as-miR-31-3p treatment greatly reduced colonic miR-31-3p expression $(P<0.05)$ (Figure 6D), whereas it increased colonic expression of TNF- $\alpha$, CXCL10, and CCL2 mRNAs $(P<0.05)$ (Figure 6J), further supporting the notion that miR-31-3p antagonism in vivo promoted development of colitis.

\section{Intracolonic Administration of miR-31-3p Mimic Attenuates DSS-Induced Colitis}

Because the above results suggested that lower miR-31-3p colonic levels are associated with worsening of colitis, miR-31-3p was delivered by intracolonic administration of a 
A

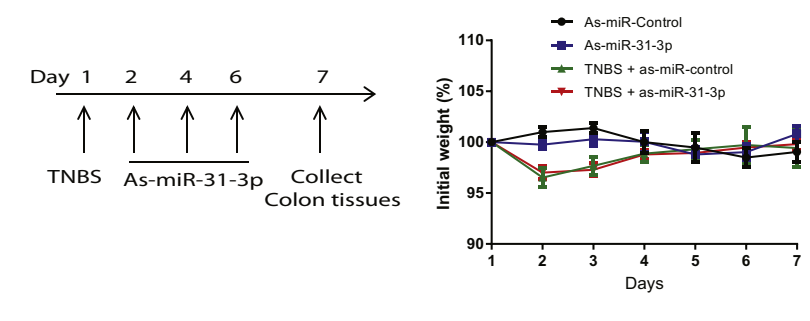

C

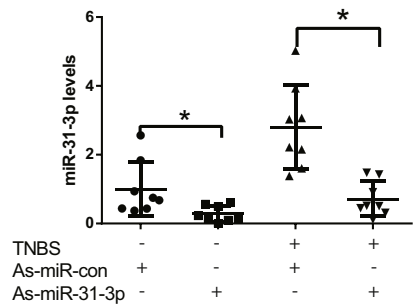

D

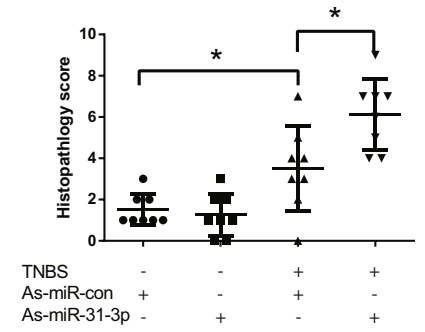

E
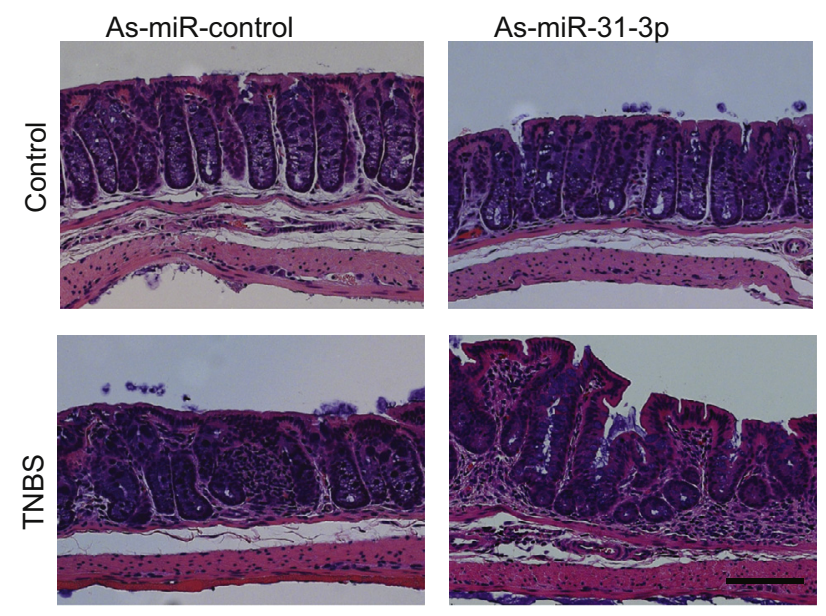

$\mathbf{F}$

G
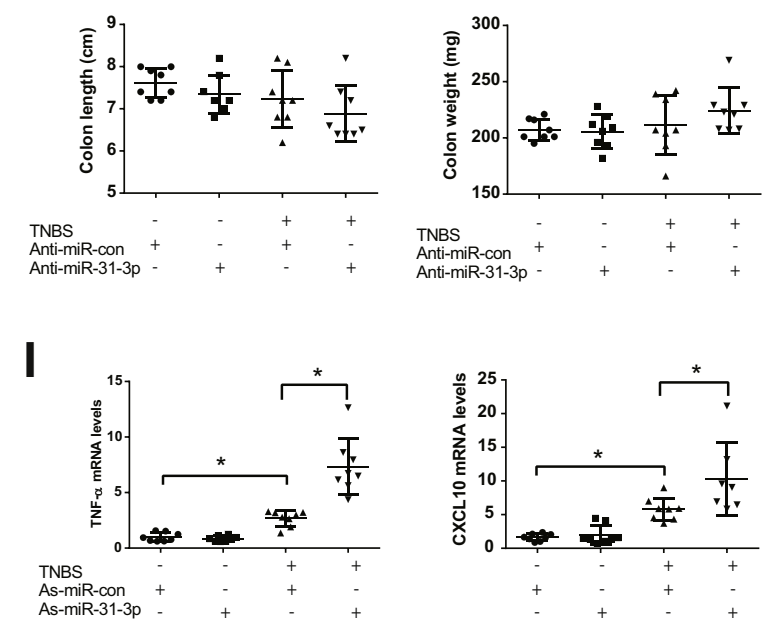

H
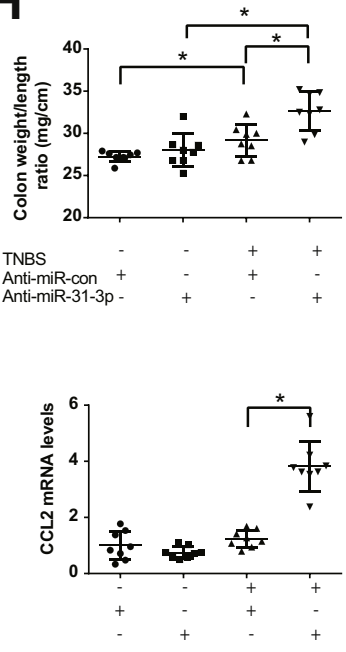

Figure 5 Antisense (as)-miR-31-3p exacerbates trinitrobenzene sulfonic acid (TNBS)induced colitis. A: Timeline of as-miR-31-3p treatment in TNBS-induced colitis. B: Percentage of initial body weight of each group of mice during treatment. C: Expression level of miR-31-3p was assessed by real-time PCR after intracolonic administration of as-miR-31-3p. D: Histopathology score of as-miR-31$3 p$-treated mice with TNBS-induced colitis. E: TNBS-induced histologic changes in colons of controls or as-miR-31-3p-treated C57BL6/J mice. $\mathbf{F}-\mathbf{H}$ : Colon length, colon weight, and colon weight-to-length ratio of each group of mice. I: Expression of tumor necrosis factor (TNF)- $\alpha$, CXCL10, and chemokine (C-C motif) ligand 2 (CCL2) in the colon tissue of as-miR31-3p-or as-miR-control-treated TNBS mice colitis models. Data are expressed as means \pm SD. $n=8 .{ }^{*} P<0.05$. Scale bar $=$ $100 \mu \mathrm{m}$. Con, control.
miR-31-3p or a control mimic (Materials and Methods) (Figure 7A). No differences were found in body weights between the groups (Figure 7B). However, treatment with miR31-3p mimic reduced histologic damage and disease activity compared with mice treated with control mimic in the DSS model (Figure 7, C and G-J). Compared with control mimicor vehicle-treated mice, miR-31-3p mimic treatment in DSSexposed mice increased colonic levels of miR-31-3p $(n=8$; $P<0.05$ ) (Figure 7D), decreased DAI (Figure 7G), histopathology score (Figure $7 \mathrm{H}$ ), and immune cell infiltration (Figure 7I). A small yet significant increase was also observed in colon length in response to miR-31-3p mimic treatment in
DSS-exposed mice $(n=8 ; P<0.05)$ (Figure $7 \mathrm{E}$ ), whereas no differences were observed in colon weight (Figure $7 F$ ). The mechanism by which miR-31-3p increased colon length in DSS-exposed mice was not clear, but it may involve a yet undescribed proliferative pathway activated by this miRNA. DSS with control mimic treatment increased expression of TNF- $\alpha$, CXCL10, and CCL2 in the mouse colon compared with mice without treatment, whereas miR-31-3p mimic treatment reduced expression of these cytokines induced ( $n=8 ; P<0.05$ ) (Figure $7 \mathrm{~J})$. These results suggested that miR-31-3p played a pivotal role in maintaining mucosal homeostasis during inflamed conditions. 
A

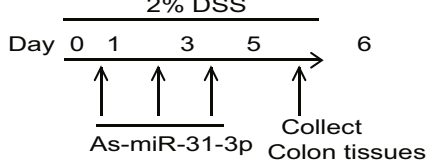

B

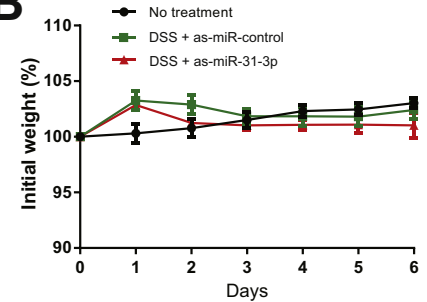

C

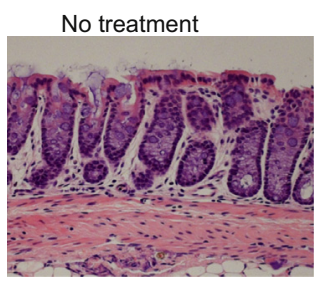

DSS + as-miR-control

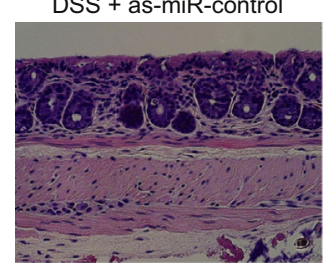

DSS + as-miR-31-3p

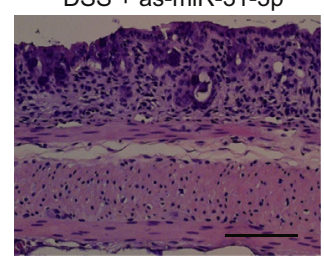

D
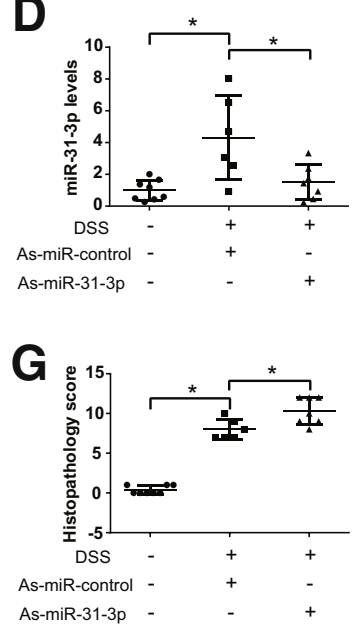

J

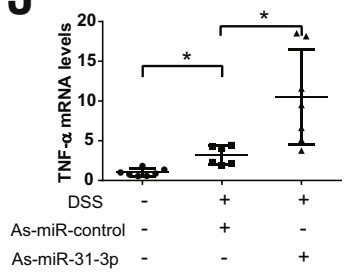

E
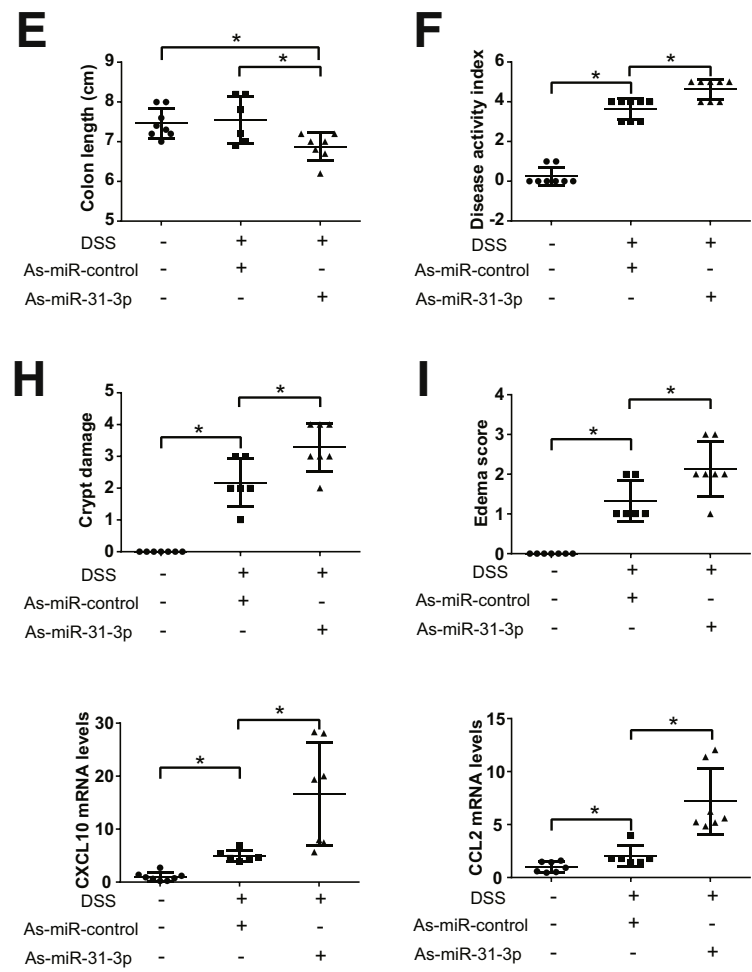

Figure 6 Antisense (as)-miR-31-3p exacerbates dextran sodium sulfate (DSS)-induced colitis. A: Timeline of as-miR-31-3p treatment in $2 \%$ DSSinduced colitis. B: Percentage of initial body weight of each group of mice during treatment. C: Histologic changes in colons of controls or as-miR31-3p-treated C57BL6/J mice in DSS colitis model. D: Expression level of miR-31-3p after intracolonic administration of as-miR-31-3p. E: Colon length of each group of mice. F: Disease activity index scores of as-miR-31-3p-treated mice with DSS-induced colitis. * G: Histopathology score of as-miR-31-3ptreated mice with DSS-induced colitis. H: Crypt damage score of as-miR-31-3p-treated mice with DSS-induced colitis. I: Edema score of as-miR31-3p-treated mice with DSS-induced colitis. J: Expression of tumor necrosis factor (TNF)- $\alpha$, CXCL10, and chemokine ( $\mathrm{C}-\mathrm{C}$ motif) ligand 2 (CCL2) in the colon tissue of as-miR-31-3p- or anti-miR-controltreated DSS-induced colitis models. Data are expressed as means \pm SD. $n=8 .{ }^{*} P<0.05$. Scale bar $=100 \mu \mathrm{m}$.

\section{miR-31-3p Targets RhoA in Colonic Epithelial Cells}

Because miRNAs negatively regulated gene expression by binding to complementary sequences in the $3^{\prime}$ UTR of their target genes, studies were performed to identify the direct downstream target of miR-31-3p by using bioinformatics. With the use of the miRNA target prediction program from the RNA22 version 2 miRNA-target detection software ${ }^{35}$ ( $h t t p s: / / ~$ cm.jefferson.edu/rna22/Interactive, last accessed November $6,2015)$, the presence of one binding site was identified for miR-31-3p in the $3^{\prime}$ UTR of human RhoA mRNA sequence (NM_001664.3) (Figure 8A). Previous studies also indicated that RhoA may be a functional target of miR-31-3p in oral cancer cell carcinogenesis. ${ }^{19}$ In addition, RhoA was likely a part of a SP, NK-1R inflammatory signaling pathway in human colonocytes. ${ }^{10}$ To elucidate the effects of miR-31-3p on RhoA protein expression, NCM460-NK-1R cells were transfected with miR-31-3p mimic or its control, and after 24 hours cells lysates were subjected to Western blot analysis. Overexpression of miR-31-3p decreased RhoA protein level $(n=3 ; P<0.05)$ (Figure $8 \mathrm{~B})$ and reduced RhoA activity in response to SP stimulation (Figure 8C). Conversely, silencing miR-31-3p increased RhoA protein levels (Supplemental Figure S4A) and RhoA activity in human colonic epithelial cells (Supplemental Figure S4 B). Of importance, luciferase activity assays by using plasmids that contained the miR-31$3 p$ binding site in the $3^{\prime}$ UTR of RhoA indicated that cells transfected with a miR-31-3p mimic had lower RhoA-3' UTRdriven luciferase activity that control-miRNA-mimic-treated cells $(n=3 ; P<0.05)$ (Figure 8D). Of importance, when the 
A

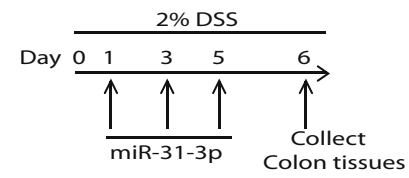

C
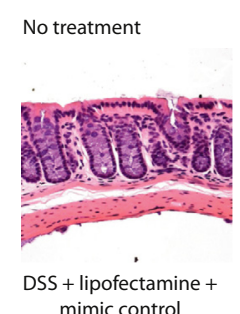
mimic control

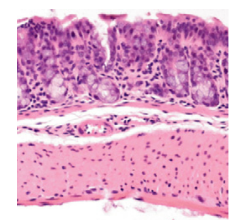

E

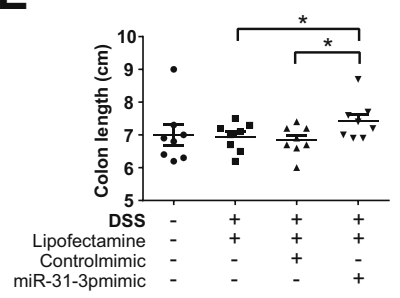

B

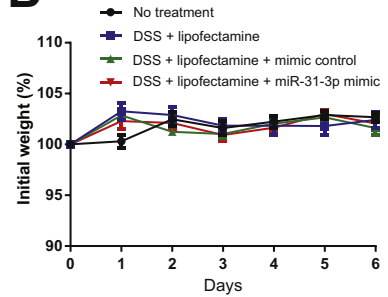

D

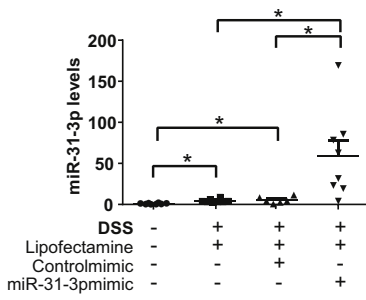

G
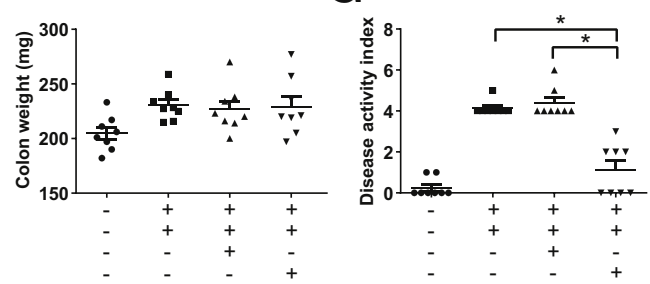

H
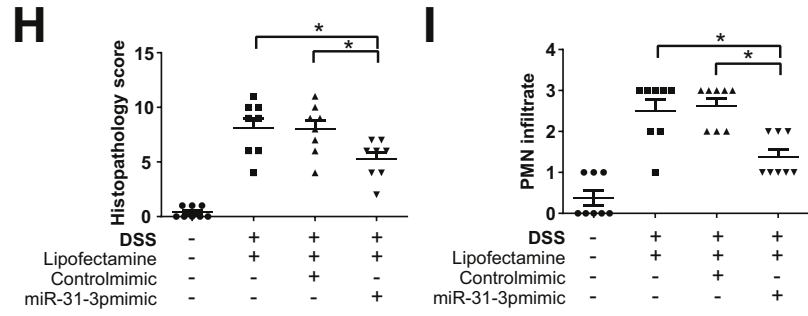

$\mathbf{J}$

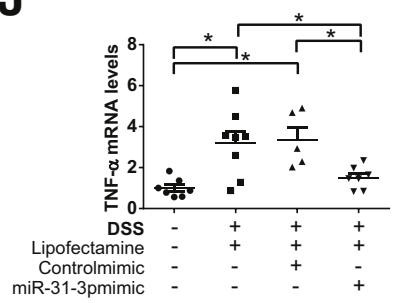

DSS + lipofectamine

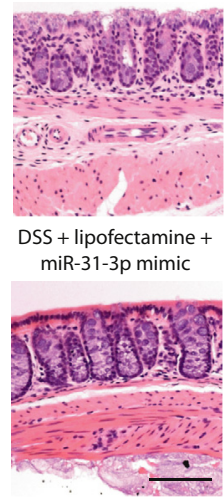

$\mathbf{F}$

Figure 7 miR-31-3p mimic treatment reduces the intestinal inflammatory response in dextran sodium sulfate (DSS)-induced colitis. A: Timeline of miR-31-3p mimic treatment in $2 \%$ DSS-induced colitis. B: Percentage of initial body weight of each group of mice during treatment. C: Histologic changes in colons of controls or miR-31-3p mimictreated C57BL6/J mice in DSS colitis model. D: Expression level of miR-31-3p after intracolonic administration of miR-31-3p mimic. E: Colon length of each group of mice. F: Colon weight of each group of mice. G: Disease activity index scores of miR-31$3 p$ mimic-treated mice with DSS-induced colitis. H: Histopathology score of miR-31-3p mimictreated mice with DSS-induced colitis. I: Polymorphonuclear leukocyte (PMN) infiltration score of miR-31-3p mimic-treated mice with DSS-induced colitis. J: Expression of tumor necrosis factor (TNF)- $\alpha$, CXCL10, and chemokine (C-C motif) ligand 2 (CCL2) in the colon tissue of miR-31-3p mimic- or control mimic-treated DSS-induced colitis models. Data are expressed as means \pm SD. $n=8 .{ }^{*} P<0.05$. Scale bar $=100 \mu \mathrm{m}$.

miR-31-3p-binding region was mutated, the reduction of luciferase activity induced by miR-31-3p overexpression was blocked (Figure 8D), suggesting that miR-31-3p directly regulated RhoA expression. To further assess the impact of RhoA in colonic epithelial cell inflammatory signaling in response to SP, NCM460-NK-1R cells were transduced with adenovirus expressing constitutively active RhoA or control adenovirus as described in Materials and Methods. RhoA expression was greatly increased in these cells infected with Ad-RhoA compared with control adenovirus-infected cells (Supplemental Figure S5). These results demonstrated that constitutively active RhoA significantly enhanced SP-induced CCL2, IL-6, and TNF- $\alpha$ mRNA expression $(n=3 ; P<0.05)$ (Figure $8 \mathrm{E}$ ), whereas RhoA activation in the absence of SP 

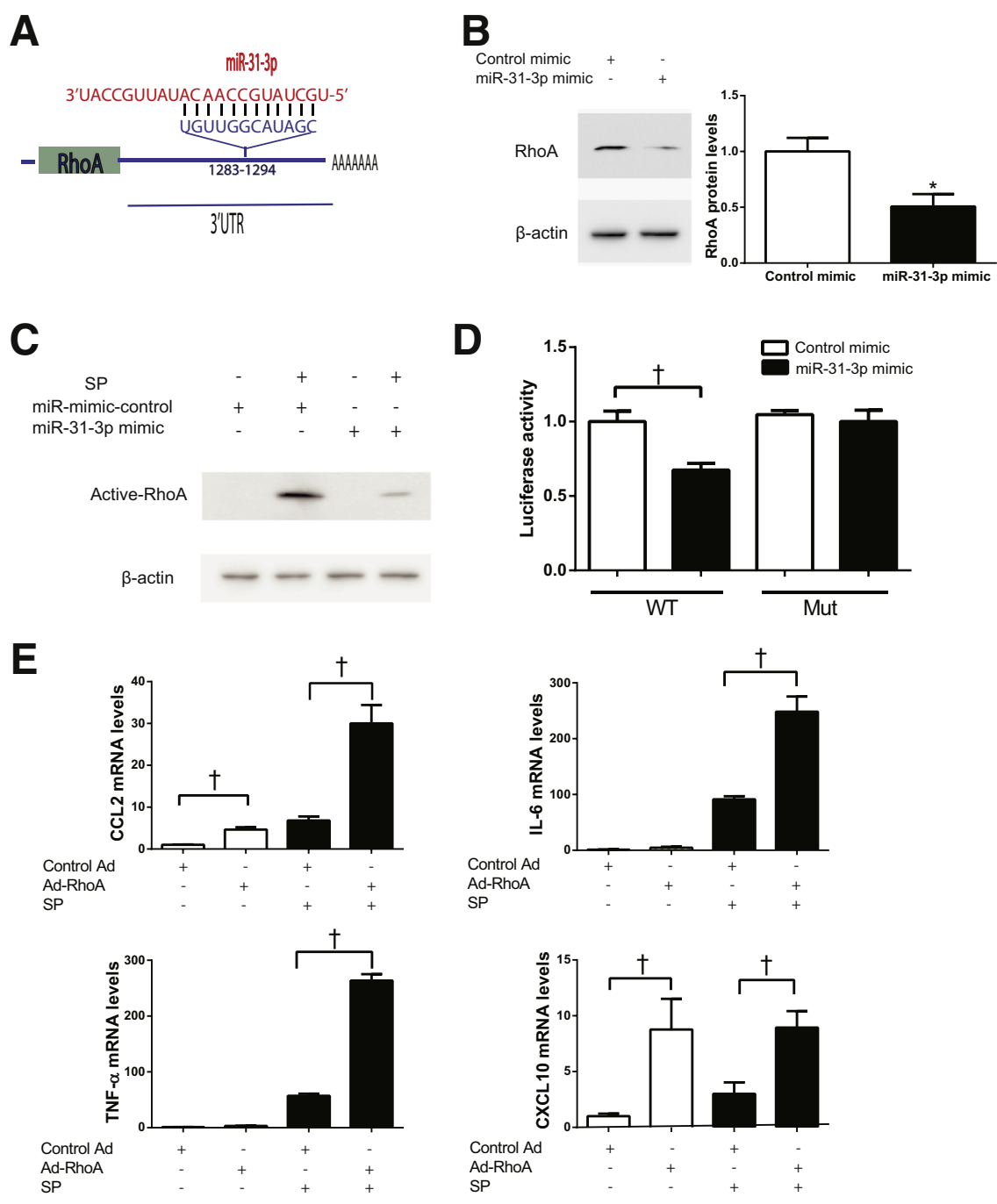

Figure 8 miR-31-3p targets RhoA in colonic epithelial cells. A: Human RhoA mRNA contains a predicted miR-31-3p binding site. B: Overexpression of miR-31-3p inhibits RhoA protein expression in NCM460-neurokinin-1 receptor (NK1R) cells. C: Overexpression of miR-31-3p inhibits RhoA protein activation in response to substance $P(S P)$ stimulation for 10 minutes in NCM460-NK$1 R$ cells. D: Wild-type (WT) or mutant (Mut) RhoA $3^{\prime}$ untranslated region (UTR) luciferase constructs were cotransfected with miR-31-3p mimic or control mimic in NCM460-NK-1R cells. Luciferase activity was determined 24 hours after transfection, and normalized luciferase activity is shown. E: Chemokine (C-C motif) ligand 2 (CCL2), IL-6, tumor necrosis factor (TNF)- $\alpha$, and CXCL10 mRNA expression in response to SP stimulation of NCM460-NK-1R cells with constitutive activated RhoA. Data are expressed as means \pm SD. $n=3$ experiments. ${ }^{*} P<0.05$ versus control; ${ }^{\dagger} P<0.05$. $\mathrm{Ad}$, adenovirus.

induced CCL2 and CXCL10 expression $(n=3, P<0.05)$. However, RhoA silencing by siRNA transfection (Supplemental Figure S6A) greatly reduced CCL2, IL-6, TNF- $\alpha$, and CXCL10 mRNA levels in response to SP stimulation in NCM460-NK-1R cells (Supplemental Figure S6B). Collectively, these results suggested that miR31-3p regulates SP-induced cytokine gene expression by targeting RhoA (Figure 9).

\section{Discussion}

SP by NK-1R regulates intestinal inflammation both in the acute and chronic stages of colitis. ${ }^{6}$ In this study, the contribution of SP-regulated miR-31-3p was examined in the pathophysiology of intestinal inflammation and the mechanism of this response was examined in vitro and in vivo. The results indicate that this SP-NK-1R-dependent miR-31-3p-RhoA circuit is activated in human colonic epithelial cells and UC specimens (Figure 4), suggesting an important role for $\mathrm{NK}-1 \mathrm{R}$-dependent miRNA regulation in colitis.
Silencing of endogenous colonic miR-31-3p regulates experimental colitis in two different mouse chemical models. To suppress miRNA expression in vivo, the antisense sequence of the miRNA has to be chemically modified because naked RNA is rapidly degraded because of nuclease enzymatic degradation. ${ }^{36}$ Modifications introduced in our miR-31-3p inhibitor, such as the locked nucleic acid and the phosphorothioate bonds, confer nuclease stability, increase binding affinity, and facilitate the entrance into the gut tissue. ${ }^{37}$ On in vivo gene silencing of colonic miR-31-3p, mucosal histologic damage worsened, and colonic mRNA levels of TNF- $\alpha$, CCL2, and CXCL10 were increased in both TNBS- and DSS-induced colitis (Figures 5 and 6). TNF- $\alpha$, CCL2, and CXCL10 have been associated with the pathophysiology of IBD. Neutralization of TNF- $\alpha$ with monoclonal antibodies represents one of the most important therapies in IBD. ${ }^{38}$ In addition, CXCL10 is increased in inflamed colons of IBD patients and stimulates monocyte, natural killer, and T-cell migration. ${ }^{39,40}$ The CCL2 gene is located at 17q12, an IBD susceptibility locus, and it plays a critical role in IBD. ${ }^{41}$ 


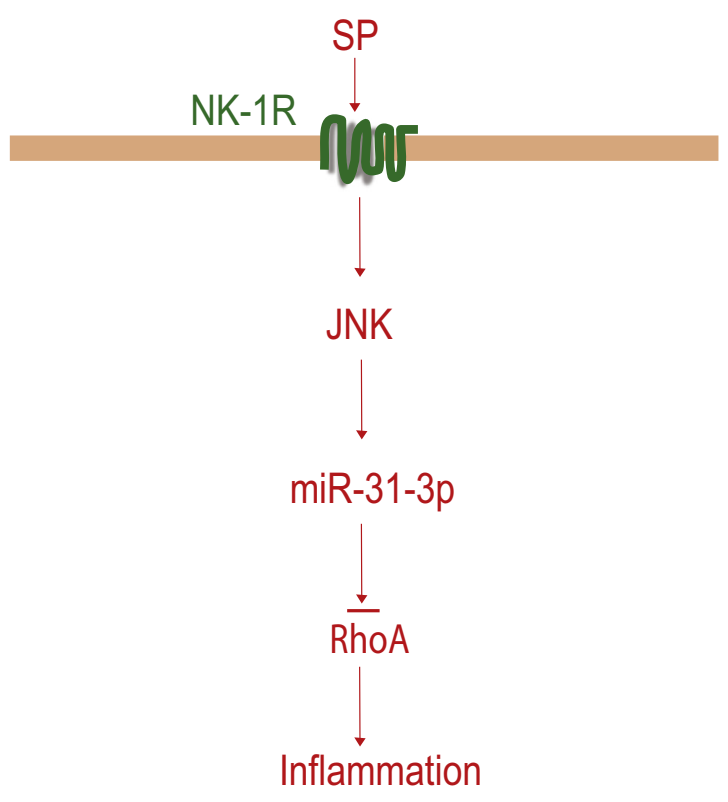

Figure 9 Schematic representation of proposed substance P (SP)-miR31-3p signaling pathway in human colonic epithelial cells. After binding to the neurokinin-1 receptor (NK-1R), SP stimulates miR-31-3p by c-Jun Nterminal kinase (JNK) activation in human colonic epithelial cells. miR-31$3 p$ regulates inflammation by down-regulating RhoA expression.

Although most published studies focus on the suppression of miRNA expression, a novel miR-31-3p mimic was used, aiming to increase its expression in IBD animal models. Specifically, a double-stranded RNA-harboring phosphorothioate and 2-methoxy modifications bound to a cholesterol conjugate that is able to load into the RISC complex, were designed. ${ }^{37}$ Specifically, miR-31-3p overexpression in vivo ameliorated DSS-induced colitis, as shown by reduced DAI and reduced immune cell infiltration and expression of cytokines, such as TNF- $\alpha$, CCL2, and CXCL10. Another potential strategy for miR-31-3p restoration may be through the use of an adeno-associated viral vector. Adeno-associated viral vectors have been demonstrated to achieve miRNA restora$\operatorname{tion}^{42}$; however, the miRNA mimic strategy may be safer because of potential immunogenicity induced by the adenoassociated viralcapsid. ${ }^{43}$ Thus, these results support the notion that miR-31-3p plays an important role in maintaining mucosal homeostasis in the presence of inflammatory stimuli through inhibition of expression of functionally important IBD-related proinflammatory genes.

miR-31-3p is primarily expressed intracellularly in colonic epithelial cells as shown by in situ hybridization in human IBD colon tissues and in the colonic mucosa of mice during TNBSand DSS-induced colitis (Figure 4). These findings are not surprising because expression of several other colitisassociated miRNAs has been observed, primarily intracellularly in colonic epithelial cells, including miR-133a, miR-221$5 \mathrm{p}$, and miR-214 ${ }^{18,24,44}$, with little expression in the subepithelial compartment. ${ }^{18,24,44}$ As in the case with miR-31-3p described in this present study, all of the above miRNAs played a functional role in the development of colitis. ${ }^{18,24,44}$
miRNAs play a regulatory role in gene expression. miR31-3p has been shown to target RhoA in oral squamous cell carcinoma. ${ }^{19}$ Our data demonstrate that RhoA is a target of miR-31-3p in human colonic epithelial cells. Increased activation of RhoA is evident in inflamed intestinal mucosa of IBD patients and rats with TNBS-induced colitis. ${ }^{45}$ RhoA protein levels were increased in miR-31-3p-silenced colonic epithelial cells (Supplemental Figure S4A), whereas active-RhoA was increased in response to 10 minutes of SP stimulation (Supplemental Figure S4B), consistent with the miR-31-3p overexpression results (Figure 8, B and C). RhoA silencing in colonocytes down-regulated RhoA expression, as well as CCL2, IL-6, TNF- $\alpha$, and CXCL10 mRNA expression in response to SP stimulation (Supplemental Figure S6). These results suggest that SPmiR-31-3p-regulated RhoA is proinflammatory in vivo and in vitro. In other studies, inhibition of Rho kinase prevents inflammation in the intestine ${ }^{45}$ and in rheumatoid arthritis, ${ }^{46}$ whereas our previous findings suggest that RhoA plays a proinflammatory role in SP-exposed colonocytes, ${ }^{10}$ consistent with the findings of the present study (Figure $8 \mathrm{E}$ ).

These results show increased expression of miR-31-3p in colonic biopsies from UC patients (Figure 4, A and B) and experimental colitis, indicating an anti-inflammatory mechanism by which miR-31-3p reduces RhoA expression during colitis. A recent study showed that RhoA KO mice are associated with spontaneous mucosal inflammation in the small intestine but not in the colon. There is no significant difference in the colon tissue histopathology score, $\mathrm{CD} 4^{+} \mathrm{T}$ cell, or TNF$\alpha$ levels in the intestinal epithelial RhoA KO mice compared with wild-type mice, ${ }^{47}$ which seems contradictory to our study. This discrepancy might be due to the $\mathrm{KO}$ in vivo RhoA approach used by Lopez-Posada et $\mathrm{al}^{47}$ versus pharmacologic inhibition by its upstream regulator miR-31-3p RhoA protein in wild-type mice in our study. Recently, it was reported that inhibition of the Rho/Rho kinase pathway by administration of the Rho inhibitor prevents lipopolysaccharide-induced inflammation in mice, ${ }^{48}$ which is consistent with our findings.

\section{Conclusions}

We have identified miR-31-3p as an SP-responsive miRNA that regulates RhoA protein expression and activity in human colonic epithelial cells in vitro, affecting experimental colitis in vivo. Our studies support the notion for a therapeutic potential of miR-31-3p mimics in diverse inflammatory conditions, including UC.

\section{Acknowledgment}

We thank the University of California Los Angeles Translational Pathology Core Laboratory for their technical assistance of experimental colitis studies. 


\section{Supplemental Data}

Supplementary data related to this article can be found at https://doi.org/10.1016/j.ajpath.2017.10.023.

\section{References}

1. Valencia-Sanchez MA, Liu J, Hannon GJ, Parker R: Control of translation and mRNA degradation by miRNAs and siRNAs. Genes Dev 2006, 20:515-524

2. Iliopoulos D: MicroRNA circuits regulate the cancer-inflammation link. Sci Signal 2014, 7:pe8

3. Nguyen HT, Dalmasso G, Muller S, Carriere J, Seibold F, DarfeuilleMichaud A: Crohn's disease-associated adherent invasive Escherichia coli modulate levels of microRNAs in intestinal epithelial cells to reduce autophagy. Gastroenterology 2014, 146:508-519

4. Koukos G, Polytarchou C, Kaplan JL, Morley-Fletcher A, GrasMiralles B, Kokkotou E, Baril-Dore M, Pothoulakis C, Winter HS, Iliopoulos D: MicroRNA-124 regulates STAT3 expression and is down-regulated in colon tissues of pediatric patients with ulcerative colitis. Gastroenterology 2013, 145:842-852.e2

5. Wu F, Zikusoka M, Trindade A, Dassopoulos T, Harris ML, Bayless TM, Brant SR, Chakravarti S, Kwon JH: MicroRNAs are differentially expressed in ulcerative colitis and alter expression of macrophage inflammatory peptide-2 alpha. Gastroenterology 2008, 135:1624-1635.e24

6. Steinhoff MS, von Mentzer B, Geppetti P, Pothoulakis C, Bunnett NW: Tachykinins and their receptors: contributions to physiological control and the mechanisms of disease. Physiol Rev 2014, 94: 265-301

7. Pothoulakis C, Castagliuolo I, LaMont JT, Jaffer A, O'Keane JC, Snider RM, Leeman SE: CP-96,345, a substance P antagonist, inhibits rat intestinal responses to Clostridium difficile toxin A but not cholera toxin. Proc Natl Acad Sci U S A 1994, 91:947-951

8. Stucchi AF, Shebani KO, Leeman SE, Wang CC, Reed KL, Fruin AB, Gower AC, McClung JP, Andry CD, O'Brien MJ, Pothoulakis C, Becker JM: A neurokinin 1 receptor antagonist reduces an ongoing ileal pouch inflammation and the response to a subsequent inflammatory stimulus. Am J Physiol Gastrointest Liver Physiol 2003, 285: G1259-G1267

9. Castagliuolo I, Riegler M, Pasha A, Nikulasson S, Lu B, Gerard C, Gerard NP, Pothoulakis C: Neurokinin-1 (NK-1) receptor is required in Clostridium difficile- induced enteritis. J Clin Invest 1998, 101: $1547-1550$

10. Zhao D, Kuhnt-Moore S, Zeng H, Pan A, Wu JS, Simeonidis S, Moyer MP, Pothoulakis C: Substance P-stimulated interleukin-8 expression in human colonic epithelial cells involves Rho family small GTPases. Biochem J 2002, 368:665-672

11. Karagiannides I, Kokkotou E, Tansky M, Tchkonia T, Giorgadze N, O'Brien M, Leeman SE, Kirkland JL, Pothoulakis C: Induction of colitis causes inflammatory responses in fat depots: evidence for substance P pathways in human mesenteric preadipocytes. Proc Natl Acad Sci U S A 2006, 103:5207-5212

12. Lieb K, Fiebich BL, Berger M, Bauer J, Schulze-Osthoff K: The neuropeptide substance $\mathrm{P}$ activates transcription factor NF-kappa B and kappa B-dependent gene expression in human astrocytoma cells. J Immunol 1997, 159:4952-4958

13. Tansky MF, Pothoulakis C, Leeman SE: Functional consequences of alteration of N-linked glycosylation sites on the neurokinin 1 receptor. Proc Natl Acad Sci U S A 2007, 104:10691-10696

14. Koon HW, Zhao D, Zhan Y, Moyer MP, Pothoulakis C: Substance P mediates antiapoptotic responses in human colonocytes by Akt activation. Proc Natl Acad Sci U S A 2007, 104:2013-2018

15. Joos GF, Germonpre PR, Pauwels RA: Role of tachykinins in asthma. Allergy 2000, 55:321-337
16. Goode T, O'Connell J, Anton P, Wong H, Reeve J, O'Sullivan GC, Collins JK, Shanahan F: Neurokinin-1 receptor expression in inflammatory bowel disease: molecular quantitation and localisation. Gut 2000, 47:387-396

17. Koon HW, Zhao D, Xu H, Bowe C, Moss A, Moyer MP, Pothoulakis C: Substance P-mediated expression of the pro-angiogenic factor CCN1 modulates the course of colitis. Am J Pathol 2008, 173: $400-410$

18. Fang K, Sideri A, Law IK, Bakirtzi K, Polytarchou C, Iliopoulos D, Pothoulakis C: Identification of a novel substance P (SP)-neurokinin-1 receptor (NK-1R) microRNA-221-5p inflammatory network in human colonic epithelial cells. Cell Mol Gastroenterol Hepatol 2015, 1:503-515

19. Chang KW, Kao SY, Wu YH, Tsai MM, Tu HF, Liu CJ, Lui MT, Lin SC: Passenger strand miRNA miR-31* regulates the phenotypes of oral cancer cells by targeting RhoA. Oral Oncol 2013, 49:27-33

20. Mlcochova J, Faltejskova-Vychytilova P, Ferracin M, Zagatti B, Radova L, Svoboda M, Nemecek R, John S, Kiss I, Vyzula R, Negrini M, Slaby O: MicroRNA expression profiling identifies miR$31-5 p / 3 p$ as associated with time to progression in wild-type RAS metastatic colorectal cancer treated with cetuximab. Oncotarget 2015, 6:38695-38704

21. Manceau G, Imbeaud S, Thiebaut R, Liebaert F, Fontaine $\mathrm{K}$, Rousseau F, Genin B, Le Corre D, Didelot A, Vincent M, Bachet JB, Chibaudel B, Bouche O, Landi B, Bibeau F, Leroy K, PenaultLlorca F, Van Laethem JL, Demetter P, Tejpar S, Rossi S, Mosakhani N, Osterlund P, Ristamaki R, Sarhadi V, Knuutila S, Boige V, Andre T, Laurent-Puig P: Hsa-miR-31-3p expression is linked to progression-free survival in patients with KRAS wild-type metastatic colorectal cancer treated with anti-EGFR therapy. Clin Cancer Res 2014, 20:3338-3347

22. Fang K, Zhang S, Glawe J, Grisham MB, Kevil CG: Temporal genome expression profile analysis during t-cell-mediated colitis: identification of novel targets and pathways. Inflamm Bowel Dis 2012, 18: $1411-1423$

23. Fang K, Fu W, Beardsley AR, Sun X, Lisanti MP, Liu J: Overexpression of caveolin-1 inhibits endothelial cell proliferation by arresting the cell cycle at G0/G1 phase. Cell Cycle 2007, 6: 199-204

24. Law IK, Bakirtzi K, Polytarchou C, Oikonomopoulos A, Hommes D, Iliopoulos D, Pothoulakis C: Neurotensin-regulated miR-133alpha is involved in proinflammatory signalling in human colonic epithelial cells and in experimental colitis. Gut 2015, 64:1095-1104

25. Viennois E, Chen F, Laroui H, Baker MT, Merlin D: Dextran sodium sulfate inhibits the activities of both polymerase and reverse transcriptase: lithium chloride purification, a rapid and efficient technique to purify RNA. BMC Res Notes 2013, 6:360

26. Dai X, Chen X, Chen Q, Shi L, Liang H, Zhou Z, Liu Q, Pang W, Hou D, Wang C, Zen K, Yuan Y, Zhang CY, Xia L: MicroRNA-193a$3 p$ reduces intestinal inflammation in response to microbiota via downregulation of colonic PepT1. J Biol Chem 2015, 290:16099-16115

27. Koon HW, Zhao D, Na X, Moyer MP, Pothoulakis C: Metalloproteinases and transforming growth factor-alpha mediate substance P-induced mitogen-activated protein kinase activation and proliferation in human colonocytes. J Biol Chem 2004, 279:45519-45527

28. Sun $\mathrm{P}$, Zhou K, Wang S, Li P, Chen S, Lin G, Zhao Y, Wang T: Involvement of MAPK/NF-kappaB signaling in the activation of the cholinergic anti-inflammatory pathway in experimental colitis by chronic vagus nerve stimulation. PLoS One 2013, 8:e69424

29. Assi K, Pillai R, Gomez-Munoz A, Owen D, Salh B: The specific JNK inhibitor SP600125 targets tumour necrosis factor-alpha production and epithelial cell apoptosis in acute murine colitis. Immunology 2006, 118:112-121

30. Wingender E: The TRANSFAC project as an example of framework technology that supports the analysis of genomic regulation. Brief Bioinform 2008, 9:326-332

31. Bennett BL, Sasaki DT, Murray BW, O’Leary EC, Sakata ST, Xu W, Leisten JC, Motiwala A, Pierce S, Satoh Y, Bhagwat SS, Manning AM, 
Anderson DW: SP600125, an anthrapyrazolone inhibitor of Jun N-terminal kinase. Proc Natl Acad Sci U S A 2001, 98:13681-13686

32. Renzi D, Pellegrini B, Tonelli F, Surrenti C, Calabro A: Substance P (neurokinin-1) and neurokinin A (neurokinin-2) receptor gene and protein expression in the healthy and inflamed human intestine. Am J Pathol 2000, 157:1511-1522

33. Xu LL, Warren MK, Rose WL, Gong W, Wang JM: Human recombinant monocyte chemotactic protein and other $\mathrm{C}-\mathrm{C}$ chemokines bind and induce directional migration of dendritic cells in vitro. J Leukoc Biol 1996, 60:365-371

34. Carr MW, Roth SJ, Luther E, Rose SS, Springer TA: Monocyte chemoattractant protein 1 acts as a T-lymphocyte chemoattractant. Proc Natl Acad Sci U S A 1994, 91:3652-3656

35. Miranda KC, Huynh T, Tay Y, Ang YS, Tam WL, Thomson AM, Lim B, Rigoutsos I: A pattern-based method for the identification of MicroRNA binding sites and their corresponding heteroduplexes. Cell 2006, 126:1203-1217

36. Czauderna F, Fechtner M, Dames S, Aygun H, Klippel A, Pronk GJ, Giese K, Kaufmann J: Structural variations and stabilising modifications of synthetic siRNAs in mammalian cells. Nucleic Acids Res 2003, 31:2705-2716

37. Lapierre J, Salomon W, Cardia J, Bulock K, Lam JT, Stanney WJ, Ford G, Smith-Anzures B, Woolf T, Kamens J, Khvorova A, Samarsky D: Potent and systematic RNAi mediated silencing with single oligonucleotide compounds. RNA 2011, 17:1032-1037

38. Nielsen $\mathrm{OH}$, Ainsworth MA: Tumor necrosis factor inhibitors for inflammatory bowel disease. N Engl J Med 2013, 369:754-762

39. Mendez Samperio P, Trejo A, Miranda E: Role of type I interferon in the bacillus Calmette-Guerin-induced expression of CXCL10 from human monocytes. Mediators Inflamm 2004, 13:343-348

40. Thomas S, Baumgart DC: Targeting leukocyte migration and adhesion in Crohn's disease and ulcerative colitis. Inflammopharmacology 2012, 20:1-18

41. Franke A, McGovern DP, Barrett JC, Wang K, Radford-Smith GL, Ahmad T, et al: Genome-wide meta-analysis increases to 71 the number of confirmed Crohn's disease susceptibility loci. Nat Genet 2010, 42:1118-1125

42. Kota J, Chivukula RR, O'Donnell KA, Wentzel EA, Montgomery CL, Hwang HW, Chang TC, Vivekanandan P, Torbenson M, Clark KR, Mendell JR, Mendell JT: Therapeutic microRNA delivery suppresses tumorigenesis in a murine liver cancer model. Cell 2009, 137: $1005-1017$

43. Mingozzi F, Maus MV, Hui DJ, Sabatino DE, Murphy SL, Rasko JE, Ragni MV, Manno CS, Sommer J, Jiang H, Pierce GF, Ertl HC, High KA: CD8(+) T-cell responses to adeno-associated virus capsid in humans. Nat Med 2007, 13:419-422

44. Polytarchou C, Hommes DW, Palumbo T, Hatziapostolou M, Koutsioumpa M, Koukos G, van der Meulen-de Jong AE, Oikonomopoulos A, van Deen WK, Vorvis C, Serebrennikova OB, Birli E, Choi J, Chang L, Anton PA, Tsichlis PN, Pothoulakis C, Verspaget HW, Iliopoulos D: MicroRNA214 is associated with progression of ulcerative colitis, and inhibition reduces development of colitis and colitis-associated cancer in mice. Gastroenterology 2015, 149:981-992.e11

45. Segain JP, Raingeard de la Bletiere D, Sauzeau V, Bourreille A, Hilaret G, Cario-Toumaniantz C, Pacaud P, Galmiche JP, Loirand G: Rho kinase blockade prevents inflammation via nuclear factor kappa $\mathrm{B}$ inhibition: evidence in Crohn's disease and experimental colitis. Gastroenterology 2003, 124:1180-1187

46. He Y, Xu H, Liang L, Zhan Z, Yang X, Yu X, Ye Y, Sun L: Antiinflammatory effect of Rho kinase blockade via inhibition of NF-kappaB activation in rheumatoid arthritis. Arthritis Rheum 2008, 58:3366-3376

47. Lopez-Posadas R, Becker C, Gunther C, Tenzer S, Amann K, Billmeier U, Atreya R, Fiorino G, Vetrano S, Danese S, Ekici AB, Wirtz S, Thonn V, Watson AJ, Brakebusch C, Bergo M, Neurath MF, Atreya I: Rho-A prenylation and signaling link epithelial homeostasis to intestinal inflammation. J Clin Invest 2016, 126:611-626

48. Wang C, Song S, Zhang Y, Ge Y, Fang X, Huang T, Du J, Gao J: Inhibition of the Rho/Rho kinase pathway prevents lipopolysaccharideinduced hyperalgesia and the release of TNF-alpha and IL-1beta in the mouse spinal cord. Sci Rep 2015, 5:14553 